\title{
NOVEL TACRINE AND HESPERETIN ANALOGUES: DESIGN, MOLECULAR DOCKING AND IN SILICO ADME STUDIES TO IDENTIFY POTENTIAL ACETYL CHOLINE ESTERASE INHIBITORS FOR ALZHEIMER'S DISEASE
}

\author{
YENI TAKRIN VE HESPERETIN ANALOGLARI: ALZHEIMER HASTALIĞINDA \\ POTANSIYEL ASETILKOLIN ESTERAZ INHİBITÖRLERININN AYDINLATILMASI IÇİN \\ TASARIM, MOLEKÜLER DOKING VE IN SILIIKO ADME ÇALIŞMALARI
}

\begin{abstract}
Kondapalli NARESH*1, Kanna SRUTHI ${ }^{2}$
${ }^{1}$ Department of Pharmaceutical Chemistry, G. Pulla Reddy College of Pharmacy, Osmania University, Hyderabad, India

${ }^{2}$ Department of Pharmaceutical Chemistry R.B.V.R.R Women's College of Pharmacy, Osmania University, Hyderabad, India
\end{abstract}

\begin{abstract}
Objective: Present investigationis aimed to design and identify new potential molecules to treat Alzheimer's disease from the Tacrine and Hesperetin structures via molecular modification. Acetyl cholinesterase (AChE) enzyme was selected as target, since inhibitors of AChE were successful in the management of dementia and alleviation of other symptoms.

Material and Method: In this study, two series of new Tacrine (T1-T9) and Hesperetin (H1-H9)derivatives on the basis of the structural characteristics of acetyl cholinesterase (AChE) inhibitors were designed and screened to identify potential analogues as Anti-Alzheimerdrug on the AChE (PDB ID:1DX4) using GLIDE employing extra-precision docking. The docking results (Glide score, XPscore, docking score and binding interactions) were compared with standard drug, Tacrine.

Result and Discussion: From the docking results it was found that T9 showed highest docking score among the designed compounds. The ADME properties also predicted using Qikprop application, from the above studies' potential analogues with highest AChE inhibition and excellent pharmacokinetic properties were identified.

Keywords: Acetylcholine esterase inhibitors (AChE), alzheimer's disease (AD), glide, tacrine
\end{abstract}

\footnotetext{
* Corresponding Author/SorumluYazar: Naresh Kondapalli e-mail/e-posta: naresh4nani@gmail.com
} 


\section{$\ddot{\mathbf{O Z Z}}$}

Amaç: Mevcut araştırma, Alzheimer hastalı̆̆ını tedavi etmek için Tacrin ve Hesperetin yapılarından moleküler modifikasyonla yeni potansiyel moleküller tasarlamay ve belirlemeyi amaçlamaktadır. Asetilkolinesteraz (AChE) enzimi hedef olarak seçilmiştir, çünkü AChE inhibitörleri demansin tedavisinde ve diğer semptomların hafifletilmesinde başarllı olmuştur.

Gereç ve Yöntem: Bu çalışmada, asetilkolinesteraz (AChE) inhibitörlerinin yapısal özelliklerinitemel alan iki seri yeni Takrin (T1-T9) ve Hesperetin(H1-H9) türevleri tasarlanmış ve AChE (PDB ID: 1DX4) üzerinde Anti-Alzheimer ilaç olarak potansiyel türevler belirlemek için ekstra hassasdoking uygulamasi ile GLIDE kullanarak taranmıştır. Doking sonuçları (Glide skoru, XP skoru, doking skoru ve bağlanma etkileşimleri) standart ilaç, Takrin ile karşılaştırıldı.

Sonuç ve Tartışma: Doking sonuçlarından, T9'un tasarlanan bileşikler arasında en yüksek doking skoru gösterdiği bulundu. ADME özellikleri ayrıca Qikprop uygulaması kullanılarak da öngörülmüş, yukarıdaki çalışmalardan en yüksek AChE inhibisyonuna sahip potansiyel analoglar ve mükemmel farmakokinetik özellikleri tanımlanmıştır.

Anahtar Kelimeler: Alzheimer hastalı̆̆l (AD), asetilkolinesteraz inhibitörleri (AChE), glide, takrin

\section{INTRODUCTION}

Alzheimer's disease (AD) is considered as severe neurodegenerative disease that progress with time and has complex pathophysiological events that are very difficult to diagnose in the early stage, as disease progresses it affects both the behavioral and physiological changes whichmake the treatment very challenging. Since it is most commonly seen in elder patients require a special care during the treatment period whichmakes a socio-economic burden [1]. As the older population in the United States estimated to be increased by $22 \%$ by the year 2050 , there will be also increase in AD cases in the future [2]. There are very few drugs available for the treatment and management of symptoms of the disease specially to treat the most common symptom dementia. Most of the existing drugs act by increase the levels of acetylcholine in the brain such as acetylcholine esterase inhibitors. Though many other novel targets have been explored to target ADtill date, the acetylcholine esterase inhibitors occupied the first place as the drugs of choice and gained importance. Many other drugs that target variouspathways of $\mathrm{AD}$ are currently under clinical trials and some of them are stilling drugdiscovery pipeline [3].

AChE inhibitor Tacrine is the first drug discovered and approved for the treatment of early stage Alzheimer's symptoms such as memory and cognitive performance. But after 20 years of its discovery it has been withdrawn from the US market due to its considerable hepatotoxicity by elevating the levels of alanine transaminase. In spite of its toxicity Tacrine still remains as an interesting molecule for the researchers in many drug discovery programs for the development of drugs for AD. However, in the treatment of $\mathrm{AD}$ for the management of symptoms and prevent the disease progression, drugs with antiinflammatory and antioxidant properties could helpful. They retard the neuro degeneration at a considerable level and alleviate the symptoms. Hence drugs acting on multiple targets of AD receive considerable interest due to their enhanced therapeutic effectiveness [4]. 
In the last few decades, many natural compounds have been reported for the treatment of AD. Among them flavonoids such as Luteolin, quercetin, fisetin, rutin and hesperidin were found to possess multi targeting abilities and play a crucial role in the neuroprotection. Hesperidin flavanone glucoside found in fruits of citrus family, structurally considered as $\beta-7$ rutinoside of Hesperetin in which glycon part rutinoseislinked to aglycon part Hesperetin. Recently, Parhizet al., extensivelyreviewed the molecular mechanisms responsible for hesperidin antioxidant and anti-inflammatory activity, Marziyehet al., also reviewed the neuroprotective effect of hesperidin $[5,6]$.

In view of the above observation and increase in demand of new drugs for the treatment of AD, the present investigation emphasizes on the design and identification of potent acetylcholine esterase inhibitors from the promising drugs Tacrine and a natural flavonoid Hesperetin. Tacrine was selected as parent structure for the design of Tacrine analogues, since the molecular framework proven to be a potential anti AD drug, Hesperetin was also selected for its anti-inflammatory, antioxidant and neuro protective properties, hence these analogues could exhibit multi targeted actions in the AD.

\section{Tacrine and Hesperetin analogues design strategies}

The proposed molecules were designed (Figure 1) based on the original structure of Tacrineand Hesperetin moleculesconsidering the reported SAR of these analogues. Tacrine analogues were designed (T1-T9) by the molecular modification of Tacrine which contain planner tri cyclic ring system, in some of the designed analogues T1-T7 the try cyclic ring system was retained and modifications were made on the $\mathrm{C} 5$ position of the ring $\mathrm{B}$ one of the amine hydrogen is substituted with five member substituted heterocyclic ring systems such as imidazole, and pyrazole. The idea behind the substitutions is to design simple analogues by converting the primary amine on the B ring into a secondary amine in which the one hydrogen donor is less than the parent compound, in some derivatives hydrogen bond donor group incorporated in to the side chain heterocyclic ring system to compensate the hydrogen bond donors on ring $\mathrm{B}$, in some of the analogues such as $\mathrm{T} 8$ and $\mathrm{T} 9$ the $\mathrm{C}$ ring was converted into an alkyl group and in some other analogues isosteric replacement has been carried out where trivalent $-\mathrm{CH}=$ of ring was replaced with trivalent Nitrogen- $\mathrm{N}=$.

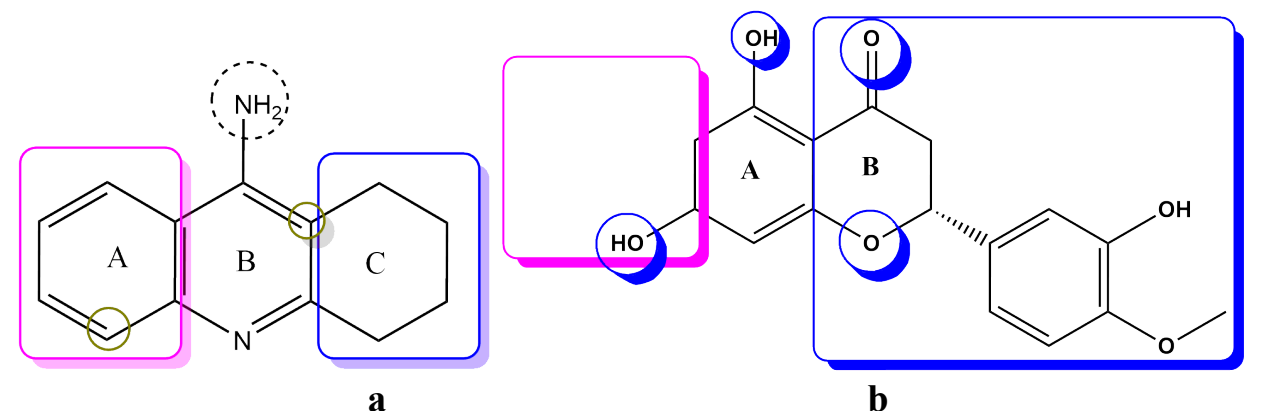

Figure 1. Design strategies for Tacrine(a) and Hesperetin(b) analogues for AChE Inhibition 
In the design of Hesperetin analogues (H1-H9, Figure 1b) the parent drug Hesperetin is highly polar due to its polar functional group on the flavanone ring system. The structural moiety of Hesperetin and functional groups arrangement on it make the molecule to to cross the blood brain barrier and proven to exhibit CNS activity.

In view of the above observations, several molecular modification techniques have been employed in the design of analogues, in some of the analogues design one of the phenolic hydroxyl group in the ring A modified into hetero aryl ether derivatives (H9), in few analogues aromatic ring is fused with heterocyclic ring systems such as pyrrolidine and Piperidine ring (H1-H4), whereas in some derivative the ring oxygen atom is isosterically replaced with bivalent $-\mathrm{NH}-(\mathrm{H} 4, \mathrm{H} 5, \mathrm{H} 7)$. All the designed analogues of Tacrine and Hesperetin (Figure 2) are diverse in their structure and also carried the basic structural framework.
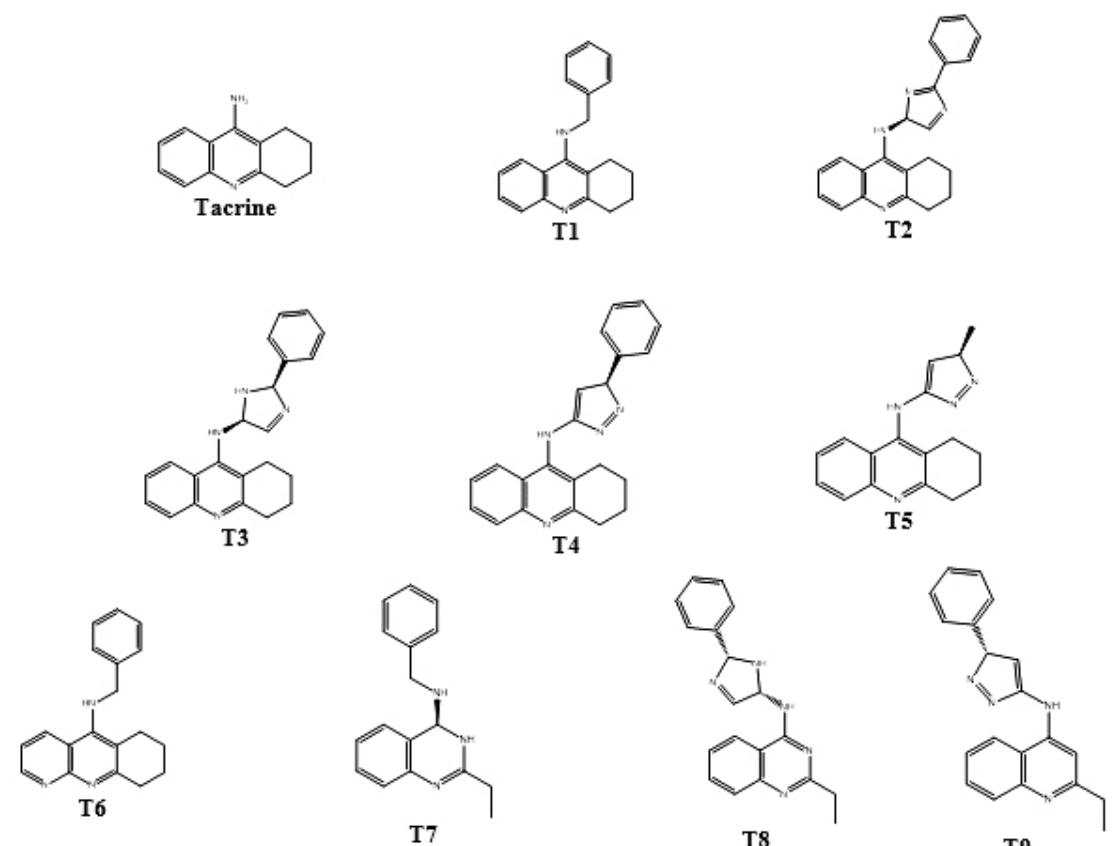

T7

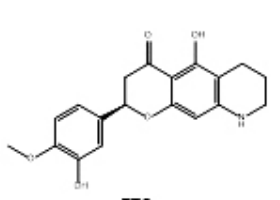

H2<smiles>CCCC1CCC(C2CC(C)C(C)CC2C)CC1C</smiles>

H5

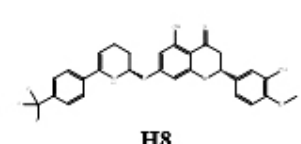

H8

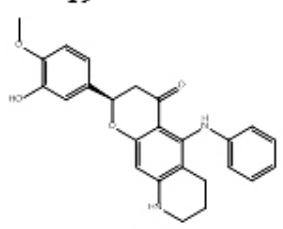

H3

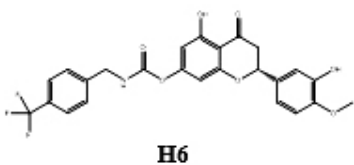

H6

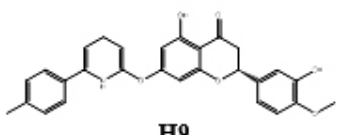

H9

Figure 2. Structures of the designed Tacrine and Hesperetin analogues 
The docking studies of these analogues using Schrodinger GLIDE [7] could reveal their binding potential within the active site of cholinesterase (Figure 3) and would helpful in the identification of potential scaffolds with enhanced inhibitory property. The druggability of designed molecules was further evaluated by computationally predicting ADME properties by Qikprop [8].

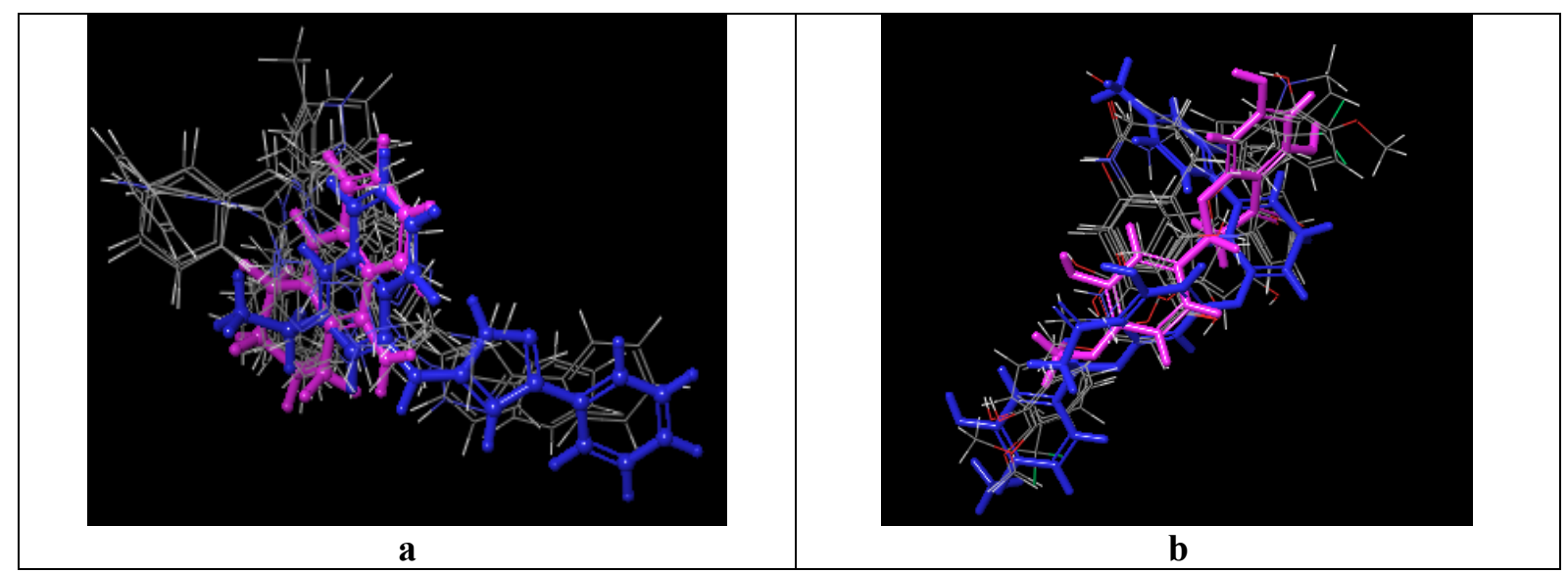

Figure 3. Clusters of binding conformation of the docked ligands a) clusters of tacrine analogues, Tacrine (Magenta) and Ligand T9 (blue) b) clusters of Hesperetin analogues, Hesperetin (Magenta) and Ligand H9 (blue)

\section{MATERIAL AND METHOD}

Molecular docking studies were carried out for the designed molecules employing standard docking protocol [9] using Schrodinger Glide software package on windows. To increase the docking speed water molecule from the protein $\mathrm{AChE}$ were removed and polar hydrogens were added, and the final structure was then energy minimized by employing OPLS forcefields. A receptor grid was identified from the position of co crystallized inhibitor molecule in the enzyme with grid points $\mathrm{X}: 36.5$, Y:65, Z:10.63 (Figure 3) and same was selected to facilitate the docking in this predefined grid. All the designed ligands, Tacrine, Hesperetin were prepared as a single energy minimized Ligprep file and they were used in docking. Extra precision docking was adopted for final docking and the results are presented (Table 1 and 2). The ADME properties (Table 4) also predicted from Ligprep files using Qikprop application in Schrodinger (Maestro).

\section{RESULT AND DISCUSSION}

In the present investigation efforts have been made to design and identify potential Anti Alzheimer's drugs which targets Acetylcholine esterase enzyme. The newly designed Tacrine and 
Hesperetin analogues were docked into the target protein AChE structure, PDB ID 1DX4. The target structure comprises a total of 585 amino acid residues and an inhibitor molecule.

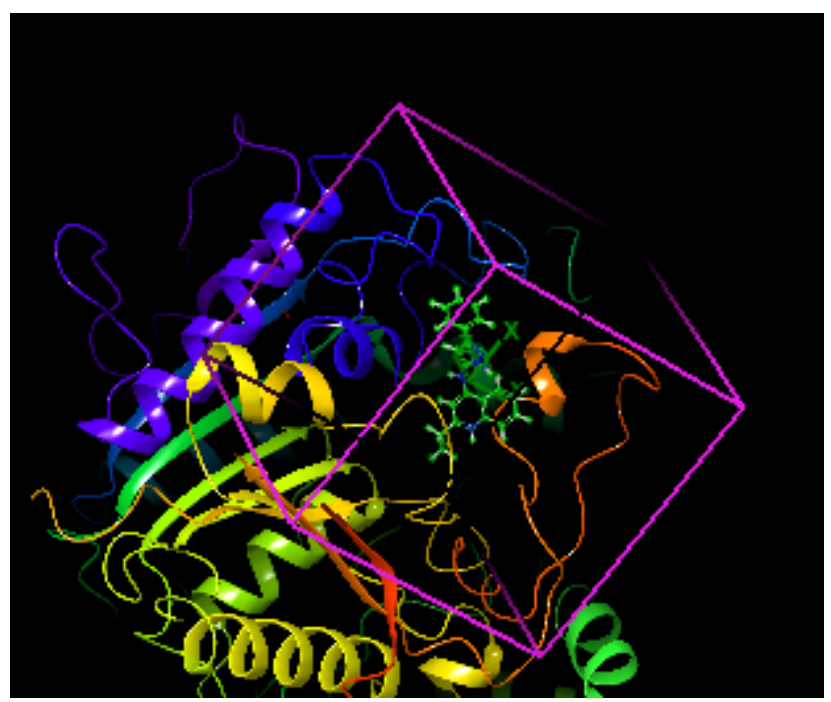

Figure 4. Selected Grid box within the protein AChE (1DX4) for docking

All the designed ligands, Tacrine, Hesperetin were prepared as a single energy minimizedLigprep file and they were used in docking by selecting extra precision docking (XP) protocol. The docking predicts the most appropriate ligand receptor complexes of the docked ligands and ranked according to the binding energies, the XP docking gave docking score and glide score for all the docked ligands from which the preliminary evaluation was made. The entire docking protocol was validated by comparing the docked conformation of the representative ligand [10] with its Co-crystal structure conformation in the protein, since the RMSD value was less than $1 \mathrm{~A}^{\mathrm{o}}$, the procedure employed was considered as valid.

Once the docking job has been completed, the anticholine esterase potency of the new analogues was evaluated by considering the three parameters, the scores (Table 1), poses and binding interactions and compared with that of standard inhibitors (Tacrine and Hesperetin). For instance, a molecule is considered to be potent when it bounds with a least binding energy and mimics the binding pose and interactions of standard drug Tacrine in the active site of AChE. Therefore, from the docking scores ligand T9 was considered as most potent among the tested ligands with a score -16.11 which is much greater than the standard Tacrine (-11.16). The interactions of T9 with AChE also mimics the Tacrine binding (Figure 5), Aromatic ring of the T9 made a $\pi-\pi$ interaction with the Trp 83, Tyr370 aromatic ring, the secondary amine hydrogen of ring B interacted with Hie480. In addition to these, the 3-phenyl pyrazolyl group on the amine of ring B was flexible enough to accommodate into the active site and its interaction with Trp85 and Trp472 of the AChE, could be the reason for its high binding affinity. Further, modification of $\mathrm{C}$ ring of the Tacrine into an ethyl group oriented toward Gly 150 also influences 
the binding. It is believed that these observations could make us to consider the T9 molecule as most potent AChE inhibitors useful for the development of new drugs for Alzheimer's disease.

Ligand T5 also considered to be potent since it bound to the target molecule active site with a docking score -15.009, Moreover, it mimics the Tacrine interactions, the Ring A and B of the tricyclic ring system is interacted via $\pi-\pi$ stacking with $\operatorname{Trp} 83$ and the other interaction also observed with Hie 480 and Tyr370(H bond)(figure 7), The pyrazole ring on the amine also mimics the orientation of T9 and also forms a Hydrogen bond with the Asn84.Ligand T4 (XP score -14.43) also bound to the AChE reproducing the same pose, orientation and binding interactions of Tacrine, it showed a $\pi-\pi$ interaction with Trp83, Tyr370, the pyrazole made another $\pi-\pi$ interaction with Trp472, Pyrazole NH forms a H Bond with Hie480, but the amine nitrogen on the $\mathrm{B}$ ring did not participate in $\mathrm{H}$ bond as it is flipped away from Hie 480 and the presence of ring $\mathrm{C}$ could prevent the rotation in the active site. Nevertheless, both ligands $\mathrm{T} 5$ and $\mathrm{T} 4$ were also considered as potent ligands for the AChE inhibition.

Table 1. Molecular docking results of Tacrine analogues on Acetylcholine esterase active site

\begin{tabular}{|r|l|r|r|r|}
\hline Entry & Compound & Docking Score & Glide Score & XP Score \\
\hline 1 & T1 & $\mathbf{- 1 3 . 6 3 1}$ & $\mathbf{- 1 3 . 6 3 1}$ & $\mathbf{- 1 3 . 6 3 1}$ \\
\hline 2 & $\mathbf{T 2}$ & $\mathbf{- 1 2 . 3 3}$ & $\mathbf{- 1 4 . 3 6 6}$ & $\mathbf{- 1 4 . 3 6 6}$ \\
\hline 3 & $\mathbf{T 3}$ & $\mathbf{- 1 2 . 0 6}$ & $\mathbf{- 1 3 . 3 7 5}$ & $\mathbf{- 1 3 . 3 7 5}$ \\
\hline 4 & $\mathbf{T 4}$ & $\mathbf{- 1 3 . 1 4 7}$ & $\mathbf{- 1 4 . 4 3}$ & $\mathbf{- 1 4 . 4 3}$ \\
\hline 5 & $\mathbf{T 5}$ & $\mathbf{- 1 4 . 8 5 8}$ & $\mathbf{- 1 5 . 0 0 9}$ & $\mathbf{- 1 5 . 0 0 9}$ \\
\hline 6 & T6 & -10.749 & -11.297 & -11.297 \\
\hline 7 & T7 & -10.839 & -13.529 & -13.529 \\
\hline 8 & T8 & -6.729 & -7.954 & -7.954 \\
\hline 9 & T9 & $\mathbf{- 1 4 . 9 9 7}$ & $\mathbf{- 1 6 . 4 0 6}$ & $\mathbf{- 1 6 . 4 0 6}$ \\
\hline 10 & Tacrine & -11.16 & -11.16 & -11.16 \\
\hline
\end{tabular}

All the other Tacrine analogues docking results were analyzed and the binding interaction and binding pose were studied (Table 1 and 3), except T8 all the other compounds showed appropriate interaction with the target enzyme AChE needed for the inhibition. Among them T2, T1 and T7 found to show highest binding affinity with Xp score $-14.366,-13.631$ and -13.529 respectively (Figure 7).

The molecular docking studies on Hesperetin analogues also revealed the binding ability within the active site of target enzyme AChE. Among the analogues tested H1-H9, ligands H9, H1 and H8 has excellent binding with an Xp scores $-11.284,-9.186,-9.177$ respectively which are greater than the parent Hesperetin (Table 2 and 3). Hence, these ligandscould be considered as potent for the AChE inhibition. However, the remaining ligands found to be weak inhibitors from the docking scores, 
nevertheless all the Hesperetin analogues docked conformation mimics the Hesperetin binding to AChE. The Hesperetin cholinesterase activity has been reported in the previous literature, this flavanone partcomprisedofthree phenolic hydroxyl groups. The analysis of the docking pose of Hesperetin in AChE showed a $\pi-\pi$ interaction of aryl group on $2^{\text {nd }}$ position of flavanone with Trp83, hydroxyl group on this aryl ring also formed a hydrogen bond with Hie480 another hydrogen bond formed between flavone phenolic hydroxyl group and Thr154(figure 6). Hes also produced other favorable interactions with the AChE.

Ligand H9 interacted with highest binding affinity XP score to AChE active site than its parent molecule Hesperetin and even with the standard Tacrine (Figure 8). The aromatic ring of the flavanone formed a $\pi-\pi$ interaction with Trp83, and the phenolic hydroxyl group of the same ring formed a hydrogen bond with Hie480, weak interaction were also observed with Dihedron pyridine with Tyr71 and another hydrogen bond is formed between the hydroxyl group of the 2-phenyl ring with Glu435 (figure 8), another hydrogen bond is observed between ring oxygen of the flavonone with Trp472. From the above observations it is clear that presence of three hydrogen bond interactions and the weak aromatic interactions responsible for the highest binding affinity of the $\mathrm{H} 9$.

Table 2. Molecular docking results of Hesperetin analogues on Acetylcholine esterase active site

\begin{tabular}{|r|l|r|r|r|}
\hline Entry & Compound & Docking Score & Glide Score & XP Score \\
\hline $\mathbf{1 1}$ & H1 & $\mathbf{- 9 . 1 8 6}$ & $\mathbf{- 9 . 1 8 6}$ & $\mathbf{- 9 . 1 8 6}$ \\
\hline 12 & H2 & -4.844 & -4.844 & -4.844 \\
\hline 13 & H3 & -6.633 & -6.633 & -6.633 \\
\hline $\mathbf{1 4}$ & H4 & $\mathbf{- 8 . 8 6 6}$ & $\mathbf{- 8 . 8 7 3}$ & $\mathbf{- 8 . 8 7 3}$ \\
\hline 15 & H5 & -8.472 & -8.479 & -8.479 \\
\hline 16 & H6 & -6.957 & -6.964 & -6.964 \\
\hline $\mathbf{1 7}$ & H7 & $\mathbf{- 8 . 8 5 9}$ & $\mathbf{- 8 . 8 5 9}$ & $\mathbf{- 8 . 8 5 9}$ \\
\hline $\mathbf{1 8}$ & H8 & $\mathbf{- 9 . 1 7 7}$ & $\mathbf{- 9 . 1 7 7}$ & $\mathbf{- 9 . 1 7 7}$ \\
\hline $\mathbf{1 9}$ & H9 & $\mathbf{- 1 1 . 2 7 9}$ & $\mathbf{- 1 1 . 2 8 4}$ & $\mathbf{- 1 1 . 2 8 4}$ \\
\hline 20 & Hesperetin & -9.026 & -9.045 & -9.045 \\
\hline
\end{tabular}

The druggability of a new molecule depends on both pharmacodynamics which means how good a molecule interacting with the target protein and pharmacokinetics, the properties of molecules to reach target such as absorption, distribution metabolism and excretion in short ADME. In recent years, medicinal chemists have been trying to predict these pharmacokinetic parameters even for the designed molecules before being synthesized. The development of many computational tools make such predictions possible and aid researchers to assess the druggability and chose only potential compounds 
for the synthesis and further studies. Such strategies would reduce the number of drug discovery failures at later stages.

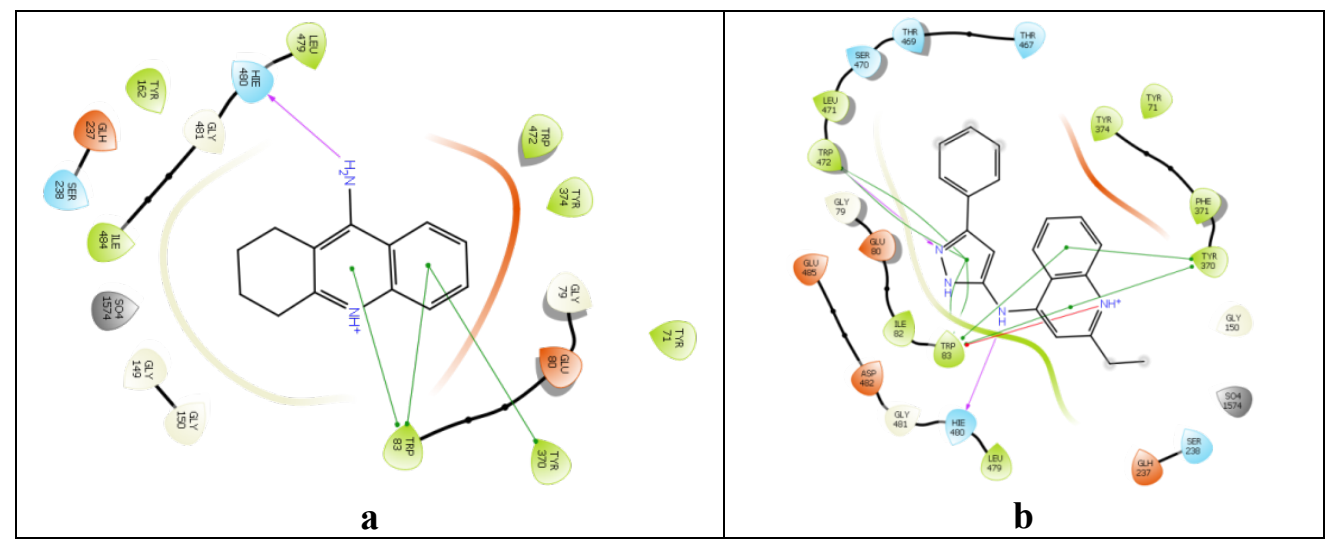

Figure 5. 2D bindinginteractions of Tacrine(a) andT9 (b)

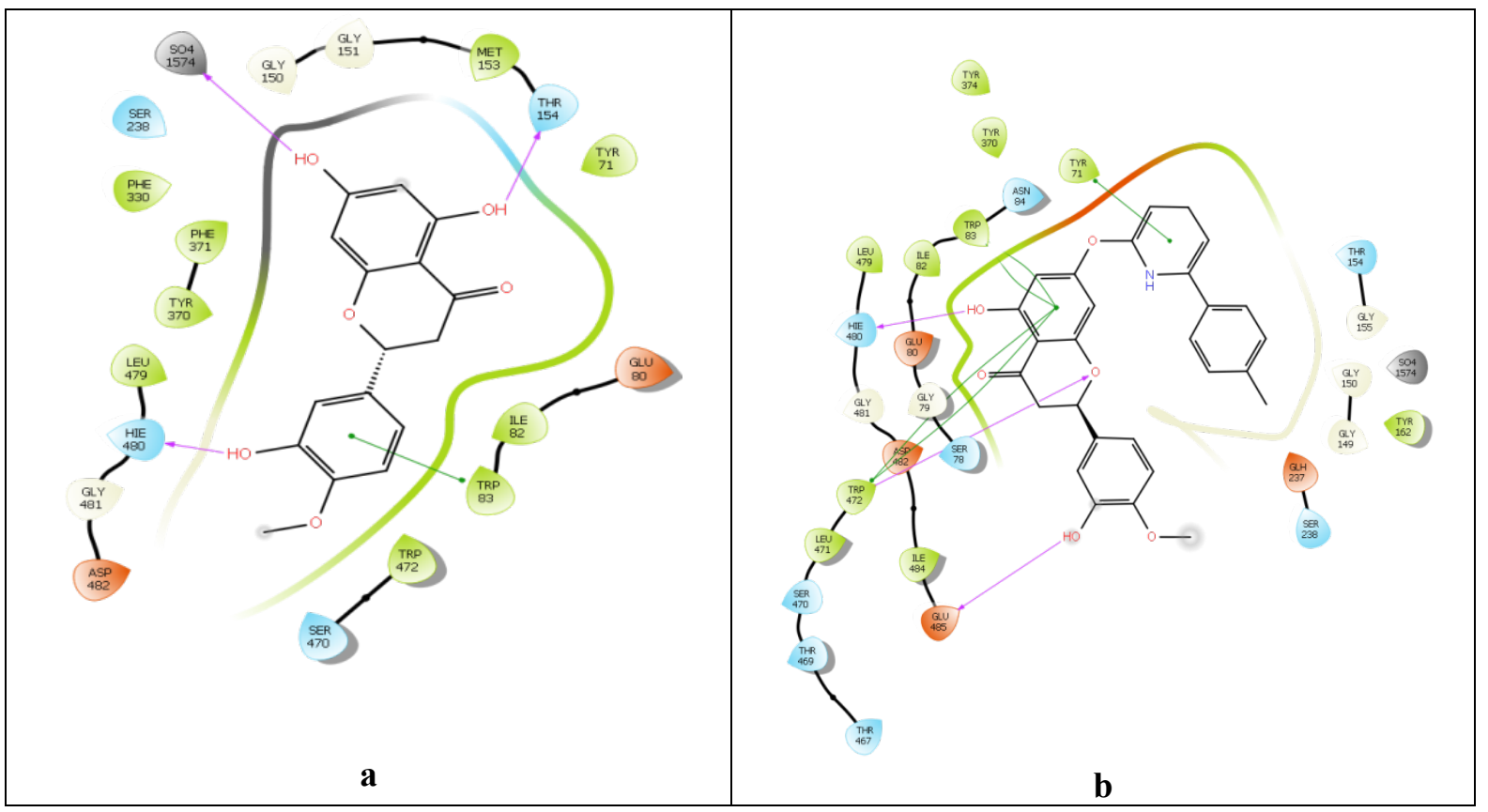

Figure 6. 2D bindinginteractions of Hesperetin(a) andH9 (b) 
Table 3. Binding interactions of docked ligands with the active site of AChE

\begin{tabular}{|r|l|l|}
\hline Entry & Compound & Interacting amino acid residues within the active site of AChE(1DX4) \\
\hline 1 & T1 & Trp83 ( $\pi-\pi$ interaction), Tyr370, Hie 480(H bond) \\
\hline 2 & T2 & Trp83( $\pi-\pi$ interaction), Tyr370, Tyr71, \\
\hline 4 & T4 & Trp472, Trp83 \\
\hline 5 & T5 & His480, Trp83( $\pi-\pi$ interaction), Tyr370(Hbond) \\
\hline 6 & T6 & Trp83( $\pi-\pi$ interaction), Tyr370( $\pi-\pi$ interaction), Tyr71, \\
\hline 7 & T7 & Trp83( $\pi-\pi$ interaction), Tyr71, Tyr370( $\pi-\pi$ interaction), Hie480(H bond) \\
\hline 8 & T8 & Trp83, Tyr370, Hie480(H bond) \\
\hline 9 & T9 & Trp83, Trp472, Tyr370, \\
\hline 10 & Tacrine & Trp83, Tyrn370, Hie480(H bond $)$ \\
\hline 11 & H1 & Tyr71, Thr 84, Tyr372, Hie480(H bond), Trp83 \\
\hline 12 & H2 & Tyr370, Glu485, Trp83, Asp432, \\
\hline 13 & H3 & Ser470, Asp432, Trp472, Hie480(H bond), Trp83 \\
\hline 14 & H4 & Trp472( $\pi-\pi$ interaction), Ser470, Hie480(H bond), Trp83, \\
\hline 15 & H5 & Trp370, Trp83, Gly149, \\
\hline 16 & H6 & Trp472, Ser470, Asp482, Tyr370( $\pi-\pi$ interaction), Gly237 \\
\hline 17 & H7 & Trp83, Glu80, Tyr370, Trp472 \\
\hline 18 & H8 & Hie480(H bond), Trp85, Thr71, Tyr370 \\
\hline 19 & H9 & Hie480, Glu485, Tyr71, Trp83, Trp472 \\
\hline 20 & Hesperetin & Thr154, Hie480, Trp83 \\
\hline
\end{tabular}




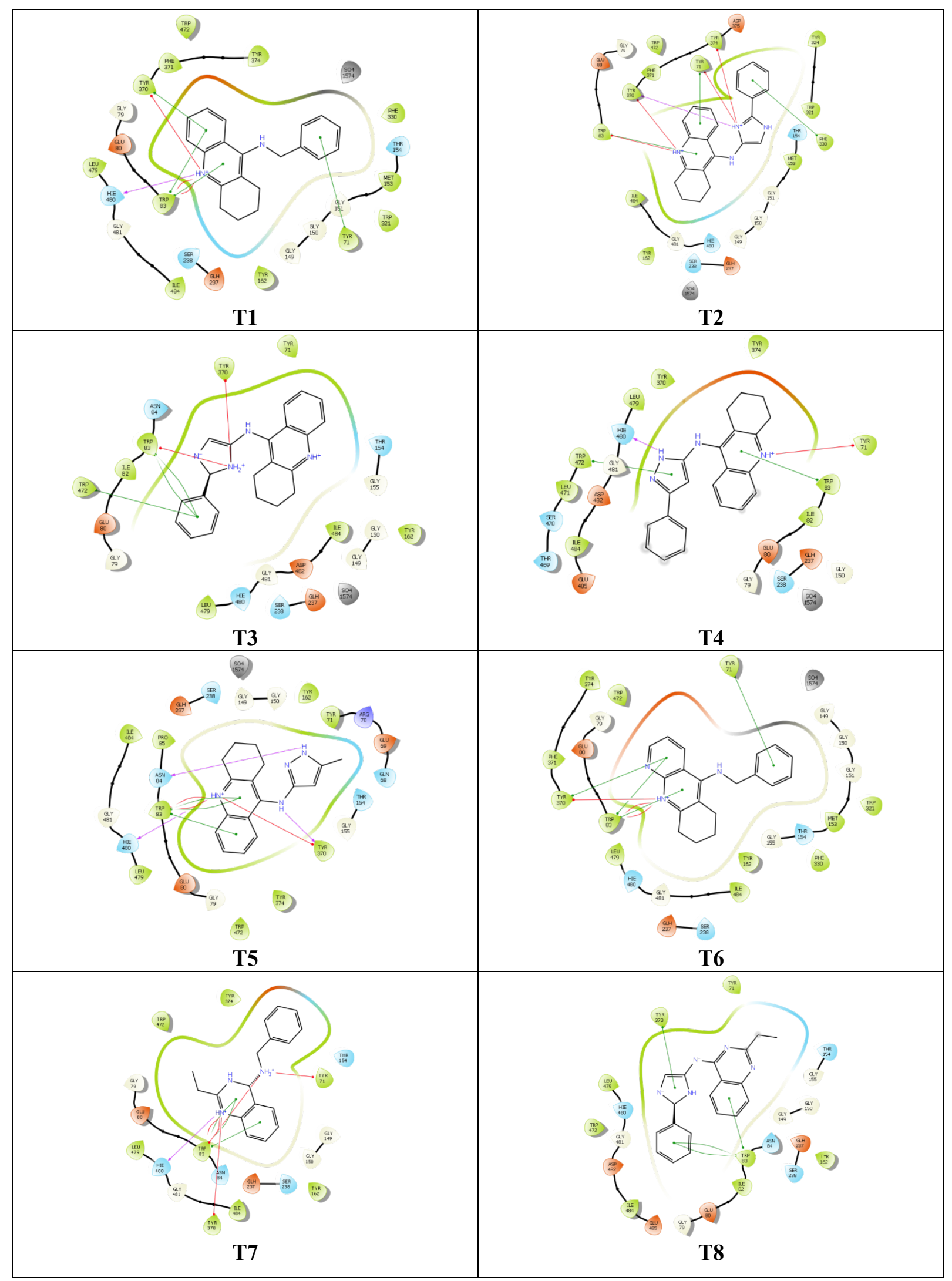

Figure 7. AChE protein and docked ligand (Tacrine analogues) complexes with 2D binding interactions 


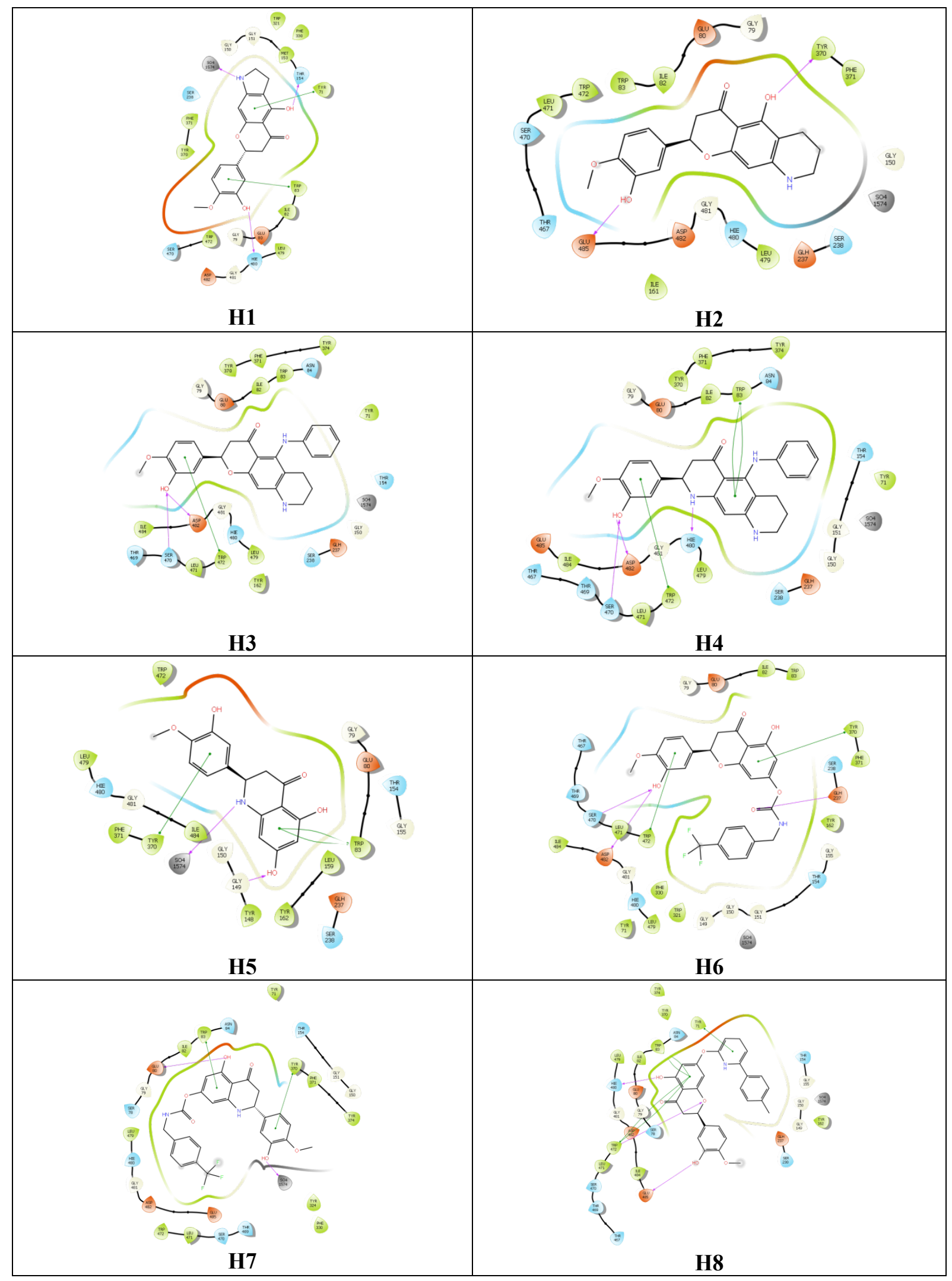

Figure 8. AChE protein and docked ligand (Hesperetin analogues) complexes with 2D binding interactions 
In the present investigation the ADME properties of all the designed analogues were predicted using Qikpropapplication in Schrodinger (Table 4), The calculated ADME properties revealed that the $\log \mathrm{P}$ values are in the range of $1.4-6.8$, the QPcaco MDCK predict the permeability of the molecule across the human intestine it predicts the mechanism of absorption through passive diffusion or active transport.All the tacrine analogues predicted to exhibit exceptional permeability through human intestinal epithelial cells. WhereastheHesperetin and its analogues exhibited moderate absorption properties. QP $\operatorname{logBB}$, represents the ability of a molecule to cross BBB, which is an important parameter forassessingCNSactivity, among all the analogues Tacrine analogues T7, T3, T1 has exceptional BBB crossing ability than the parent compound Tacrine.

Table 4. Predicted ADME properties of designed analogues calculated using QikProp

\begin{tabular}{|c|c|c|c|c|c|c|c|c|c|c|}
\hline Entry & Compound & MW & CNS & QPlogP & QPPCaco & QPlogBB & QPPMDCK & HOA & \%HOA & LogKhsa \\
\hline 1 & $\mathrm{~T} 1$ & 288.391 & 1 & 4.96 & 6077.657 & 0.174 & 3479.173 & 3 & 100 & 0.823 \\
\hline 2 & $\mathrm{~T} 2$ & 340.427 & 0 & 4.998 & 3655.089 & -0.01 & 2008.057 & 1 & 100 & 0.892 \\
\hline 3 & T3 & 342.443 & 1 & 3.959 & 638.745 & 0.222 & 337.141 & 3 & 100 & 0.713 \\
\hline 4 & $\mathrm{~T} 4$ & 340.427 & 0 & 5.136 & 2879.149 & -0.131 & 1551.53 & 1 & 100 & 0.989 \\
\hline 5 & T5 & 278.356 & 0 & 3.761 & 2486.967 & -0.155 & 1324.41 & 3 & 100 & 0.518 \\
\hline 6 & T6 & 289.379 & 0 & 4.241 & 3398.901 & -0.074 & 1856.368 & 3 & 100 & 0.597 \\
\hline 7 & $\mathrm{~T} 7$ & 265.357 & 1 & 3.345 & 1112.371 & 0.387 & 614.073 & 3 & 100 & 0.343 \\
\hline 8 & T8 & 317.393 & 0 & 3.302 & 384.766 & -0.141 & 194.929 & 3 & 92.547 & 0.447 \\
\hline 9 & T9 & 314.389 & 0 & 4.696 & 1989.139 & -0.372 & 1040.332 & 3 & 100 & 0.804 \\
\hline 10 & Tacrine & 198.267 & 1 & 2.583 & 2962.313 & 0.045 & 1600.027 & 3 & 100 & 0.067 \\
\hline 11 & H1 & 327.336 & 0 & 1.882 & 71.465 & -0.748 & 31.597 & 3 & 71.152 & 0.224 \\
\hline 12 & $\mathrm{H} 2$ & 341.363 & -2 & 2.765 & 356.23 & -1.089 & 162.115 & 3 & 88.808 & 0.341 \\
\hline 13 & $\mathrm{H} 3$ & 416.476 & -1 & 4.746 & 711.443 & -0.943 & 342.398 & 1 & 100 & 0.949 \\
\hline 14 & $\mathrm{H} 4$ & 415.491 & -1 & 4.415 & 626.743 & -0.997 & 298.557 & 1 & 100 & 0.824 \\
\hline 15 & H5 & 301.298 & -2 & 1.496 & 115.762 & -1.556 & 48.103 & 2 & 72.636 & -0.074 \\
\hline 16 & H6 & 503.431 & -2 & 4.617 & 180.962 & -1.573 & 343.95 & 1 & 81.428 & 0.773 \\
\hline 17 & $\mathrm{H} 7$ & 502.446 & -2 & 4.299 & 150.011 & -1.683 & 279.7 & 1 & 78.106 & 0.676 \\
\hline 18 & H8 & 527.496 & -2 & 6.183 & 423.122 & -1.15 & 861.848 & 1 & 84.239 & 1.376 \\
\hline 19 & H9 & 471.509 & -2 & 5.566 & 500.46 & -1.218 & 234.102 & 1 & 94.889 & 1.251 \\
\hline 20 & Hesperetin & 302.283 & -2 & 1.802 & 139.604 & -1.459 & 58.896 & 3 & 75.885 & 0.014 \\
\hline
\end{tabular}

The transportation ability to cross BBB for Hesperetin analogues is poor hence the CNS score is ranging from 0 to -2 and the percentages human oral absorption(\%HOA)found to be in the range of 75 $100 \%$,however all the Tacrine analogues except T8, have 100\% \% HOA which confers the exceptional oral bioavailability of the molecules. The predicted human serum albumin binding (Logkhsa) values were ranging from -0.067 to 1.376 which are in the recommended range of $95 \%$ known drugs. Therefore, these predicted parameterswouldhelpful in identifying druggableand orally active analogues. 
This Study further revealed that the designed analogues have appropriate pharmacokinetic properties, especially the Tacrine analogues have more potential to be druggable than the Hesperetin analogues.

In the present work Tacrine and Hesperetin analogues with diverse structures were designed to achieve acetyl choline esterase inhibitor activity to treat Alzheimer's disease. Then the designed analogues were investigated to assess the ability of the molecules to bind and inhibit the AChE, molecular docking approach was used to identify potential ligands. ADME properties also calculated and the druggability of the designed molecules were evaluated. Among the design molecules Tacrine analogues showed a potent binding and inhibition than the Hesperetin analogues, especially ligands T2, T3, T5, T7 and T9 showed highest binding than the standard Tacrine. However, H9 also exhibited highest binding with appropriate interactions necessary for inhibition. From the results of these studies it could be concluded that Tacrine analogues T2, T3, T5, T7 and T9 and Hesperetin analogue H9 have the ability to inhibit AChE and possess good ADME properties, since these molecules are druggable and could be developed as new drugs for the treatment of Alzheimer's disease.

\section{REFERENCES}

1. Alzheimer's Association. Alzheimer's disease Facts and Figures (2018). Alzheimer's Dement; 14(3), 367-429. Retrieved from https:/www.alzheimersanddementia.com/article/S15525260(18)30041-4/abstract

2. Ortman, J.M., Velkoff, V.A., Hogan, H. (2014). An Aging Nation: The Older Population in the United States, Current Population Reports, U.S. Census Bureau, Washington, D.C., 25-1140. Retieved from https://www.census.gov/prod/2014pubs/p25-1140.pdf.

3. Haibin, L., Lirong, W., Weiwei, S., \&Xiang-QunX. (2014). Advances in recent patent and clinical trial drug development for Alzheimer's disease, Pharmaceutical Patent Analyst, 3(4), 429-447.

4. Snezana, A., Kustrin, C., Kettle, D., \&Morton, W. (2018). A molecular approach in drug development for Alzheimer's disease, Biomedicine\& Pharmacotherapy, 106, 553-565.

5. Parhiz, H., Roohbakhsh, A., Soltani, F., Rezaee, R., \& Iranshahi, M. (2014). Antioxidant and AntiInflammatory Properties of the Citrus Flavonoids Hesperidin and Hesperetin: An Updated Review of their Molecular Mechanisms and Experimental Models. Phytotherapy Research, 29(3), 323331. doi: $10.1002 / p t r .5256$

6. Hajialyani, M., Farzaei, M. H., Echeverría, J., Nabavi, S., Uriarte, E., \& Sobarzo-Sánchez, E. (2019). Hesperidin as a Neuroprotective Agent: A Review of Animal and Clinical Evidence. Molecules, 24(3), 648. doi: 10.3390/molecules24030648

7. Schrödinger Release 2017-3: Glide, Schrödinger, LLC, New York, NY, 2017.

8. Schrödinger Release 2017-3: QikProp, Schrödinger, LLC, New York, NY, 2017. 
9. Naresh, K., Sruthi, K. (2018). Antimicrobial screening and molecular docking studies of imidazo [1,2-b] pyridazines as possible dihydropteroatesynthetase (Dhps) inhibitors, International Journal of Pharmacy and BiologicalSciences, 8(1), 644-651.

10. Harel, M., Kryger, G., Rosenberry, T. L., Mallender, W. D., Lewis, T., Fletcher, R. J., ... Sussman, J.L. (2000). Three-dimensional structures ofDrosophila melanogasteracetylcholinesterase and of its complexes with two potent inhibitors. Protein Science, 9(6), 1063-1072. doi: $10.1110 /$ ps.9.6.1063 